\title{
Urinary calcium excretion in children with spina bifida: correlation to level of lesion, mobility and frequency of fractures? Marcus Pauly* and Reinhold Cremer
}

\author{
Address: Children's Hospital, Dep. of Pediatric Surgery and Pediatric Urology, Amsterdamer Str. 59, 50735 Cologne, Germany \\ Email: Marcus Pauly* - pauly-castro@web.de \\ * Corresponding author
}

from 53rd Annual Meeting of the Society for Research into Hydrocephalus and Spina Bifida Belfast, UK. 24-27 June 2009

Published: 27 November 2009

Cerebrospinal Fluid Research 2009, 6(Suppl 2):S35 doi:10.1 186/1743-8454-6-S2-S35

This abstract is available from: http://www.cerebrospinalfluidresearch.com/content/6/S2/S35

(c) 2009 Pauly and Cremer; licensee BioMed Central Ltd.

\section{Background}

There are numerous methods to measure bone density, all of them are time consuming and expensive. The purpose of this study was to find an easy method to correlate mobility, risk of fractures and level of lesion in patients with spina bifida by using a simple urine test for calcium excretion.

\section{Materials and methods}

We collected clinical data and urinary calcium (and creatinine) in 42 and the serum calcium level in 36 patients with spina bifida. We correlated the lab findings to the clinical data (using a standardized questionnaire).

\section{Results}

We could not find a correlation between the urinary calcium excretion, the level of lesion, the mobility parameters (ability to stand upright, gait distance) and the frequency of fractures. There is a positive correlation between the serum calcium level, the Hoffer criteria, gait distance and the ability to stand upright in patients with spina bifida.

\section{Conclusion}

The urinary calcium cannot be used as an easy method to predict the risk of fractures due to osteopenia. The correlation of serum calcium levels mobility parameters has to be explained by further investigations with more patients and refinements of investigation methods (e.g. additional examination of parathyroid hormone). 